\title{
Studies on the Vitamin Nutrition of the Cellular Slime Mould Dictyostelium discoideum
}

\author{
By D. J. WATTS AND J. R. GUEST \\ Department of Biochemistry and Department of Microbiology, \\ University of Sheffield, Sheffield $S_{1}{ }_{2} T N$
}

(Received 9 September 1974)

\begin{abstract}
SUMMARY
Vitamin auxotrophs of Escherichia coli grown in the presence or absence of the corresponding vitamin were used as substrates for the growth of Dictyostelium discoideum strain Ax-2 in order to investigate some of the growth-factor requirements of this cellular slime mould. Compared with the growth yields observed on vitamin-sufficient auxotrophs and on a prototroph, the yields on lipoate-, folate-, thiamin- or biotin-depleted auxotrophs were low but could be restored by the addition of exogenous vitamin to the slime mould cultures. It is concluded that these four vitamins are essential nutrients for $D$. discoideum. Similar experiments with other auxotrophs were inconclusive, indicating either that the slime mould does not require pantothenate, nicotinate or vitamin $B_{6}$ or that the strains of $E$. coli were insufficiently depleted to detect such requirements. It is also concluded that cobalamin is not an essential nutrient, since the myxamoebae grew well with $E$. coli which lacks this vitamin when grown in cobalamin-free media. Similar arguments suggest that ubiquinone and vitamin $\mathrm{K}$ are also non-essential.
\end{abstract}

\section{INTRODUGTION}

The cellular slime mould Dictyostelium discoideum is being used increasingly as a model system for studying cell differentiation. Wild-type strains require bacteria as growth substrates but a mutant Ax-2, which is very useful for biochemical studies because it is capable of axenic growth in a medium containing peptone, yeast extract and inorganic salts, has been isolated (Watts \& Ashworth, 1970). However, no completely defined medium has yet been devised although it would be invaluable, particularly for furthering the progress of genetic studies with the slime mould myxamoebae. As a step towards obtaining such a medium some of the vitamin requirements of the myxamoebae have been identified by investigating myxamoebal growth on auxotrophs of Escherichia coli depleted for specific vitamins. A similar indirect approach has been used with the nematode worm Caenorhabditis elegans (S. Brenner, personal communication).

\section{METHODS}

Bacterial strains. The strains of Escherichia coli, Streptococcus faecalis and Bacillus megaterium, used as substrates for Dictyostelium discoideum, and their relevant nutritional characteristics are listed in Table I. Full details of the genotypes of these strains are not given, but when other auxotrophic markers were present they were satisfied by appropriate supplements to growth media. Stock cultures were maintained on plates of nutrient agar 


\section{Table I. Bacterial strains}

Strain

Escherichia coli $\mathrm{KI} 2$, w 4885

E. coli $\mathrm{KI} 2, \mathrm{HfrH}$

E. coli K12, W I 485lip2

E. coli K12, Т3А 58 Ipd I

E. coli K12, ATI $37 \mathrm{I}$

E. coli KI2, $\mathrm{H} 80$

E. coli KI2, KB70

E. coli K12, AN385

E. coli 518, 273-384

E. coli 15, M2

Streptococcus faecalis $R$

Bacillus megaterium
Relevant nutritional requirements

None (prototroph)

Thiamin

Lipoate or acetate plus succinate

Acetate plus succinate

Pantothenate

Nicotinate (deletion strain)

Biotin (deletion strain)

Ubiquinone-deficient (ubiA420)

p-Aminobenzoate

Vitamin $\mathbf{B}_{6}$

Folate, vitamin $B_{6}$

Biotin or aspartate at $37^{\circ} \mathrm{C}$
Reference

Bachmann (1972)

Bachmann (1972)

Herbert \& Guest (1968)

Guest \& Creaghan (1973)

Bukhari \& Taylor (1971)

Adhya \& Shapiro (1969)

Rolfe \& Onodera (1972)

Young, Leppik, Hamilton \&

Gibson (1972)

NCIB8I09; ATCC9723a

Morris \& Woods (1959)

NCIB6459; ATCC8043

NCIB7581 (White, 1972)

(E. coli and B. megaterium) or stabs of tryptose glucose agar ( $S$. faecalis) which were subcultured at monthly intervals, incubated for $15 \mathrm{~h}$ at $37^{\circ} \mathrm{C}$ and stored at $2{ }^{\circ} \mathrm{C}$.

Growth of bacterial strains. Strains of $E$. coli were grown aerobically at $37^{\circ} \mathrm{C}$ in minimal medium E (Vogel \& Bonner, I 956$)$ containing glucose $(0.4 \%$, w/v) and supplements of thiamin hydrochloride $(5 \mathrm{mg} / \mathrm{l})$, DL-lipoic acid $(20 \mu \mathrm{g} / \mathrm{l}), p$-aminobenzoic acid $(0.3 \mathrm{mg} / \mathrm{l})$, $p$-hydroxybenzoic acid ( $14 \mathrm{mg} / \mathrm{l})$, nicotinic acid $(5 \mathrm{mg} / \mathrm{l})$, calcium pantothenate $(5 \mathrm{mg} / \mathrm{l})$, D-biotin (I mg/l), pyridoxal hydrochloride $(0.2 \mathrm{mg} / \mathrm{l}$ ) or cyanocobalamin ( $\mu \mathrm{g} / \mathrm{l})$, where appropriate.

Two methods were used for preparing vitamin-deficient organisms. Wherever possible, replacement media were used to permit growth of the organisms in the absence of the vitamin. Thus lipoate-deficient bacteria were obtained by growing wi485lip2 in glucose minimal medium containing potassium acetate $(2 \mathrm{~mm})$ plus potassium succinate $(2 \mathrm{~mm})$ but no lipoate. Folate-deficient organisms were also prepared by growing mutant $273-384$ in the absence of $p$-aminobenzoate using a glucose minimal medium supplemented with vitamin free acid-hydrolysed casein $(3 \mathrm{~g} / \mathrm{l})$, thymine $(20 \mathrm{mg} / \mathrm{l})$ and adenine, guanine and xanthine (each at $5 \mathrm{mg} / \mathrm{l}$ ) according to Gibson \& Woods (1960). When no suitable replacement media were available the auxotrophs were first grown in glucose-minimal medium containing the vitamin, harvested and washed twice aseptically with saline $(\mathrm{NaCl} ; 0.9 \%$ wiv) and then starved by dilution into the same medium without vitamin for a second period of growth. In the case of vitamin $B_{6}$, the starvation medium for mutant $\mathbf{M}_{2}$ was supplemented with vitamin-free acid-hydrolysed casein ( $4 \mathrm{~g} / \mathrm{l})$, D-alanine (40 $\mathrm{mg} / \mathrm{l}$ ), L-methionine (40 $\mathrm{mg} / \mathrm{l}$ ), D-glutamic acid (40 mg/l), L-cysteine hydrochloride (30 $\mathrm{mg} / \mathrm{l})$ and $\mathrm{I}$-tryptophan (30 $\mathrm{mg} / \mathrm{l})$. The ubiquinone mutant, AN385, though blocked after $p$-hydroxybenzoate, forms about $20 \%$ of the normal level of ubiquinone in glucose medium supplemented with $p$-hydroxybenzoate (I. G. Young, personal communication) and was starved by transfer to medium lacking this growth factor. The deletion mutants $\mathrm{H} 80$ (requiring nicotinic acid) and KB7O (requiring biotin) were starved in vitamin-free minimal media for $24 \mathrm{~h}$, but the other mutants were harvested as soon as the growth rate declined in the starvation medium ( 7 to $9 \mathrm{~h}$ ) in order to limit the selection of vitamin-independent revertants. Cultures were monitored for the presence of such revertants after depletion and, if present, these never represented more than $0.1 \%$ of the population. The extent of depletion was assessed by measuring the increase in 
cell density during vitamin starvation. This corresponded to a 6o-fold increase for strain HfrH growing in the absence of thiamin, but cultures of the other mutants increased by only seven- to tenfold during vitamin deprivation.

Streptococcus faecalis was grown without aeration in medium G (Lascelles \& Woods, I954) modified by the addition of folic acid $(0.1 \mathrm{mg} / \mathrm{l})$, DL-lipoic acid $(40 \mu \mathrm{g} / \mathrm{l})$ and either pyridoxal hydrochloride $(0.2 \mathrm{mg} / \mathrm{l})$ or DL-alanine $(0.2 \mathrm{~g} / \mathrm{l})$ when vitamin $\mathbf{B}_{6}$-deficient organisms were required. This organism was also grown in folic acid assay medium (Difco) with added DL-lipoic acid $(40 \mu \mathrm{g} / \mathrm{l})$ and either folic acid ( $\mathrm{I} \mathrm{mg} / \mathrm{l})$ or the following replacement mixture (mg/l) for preparing folate-deficient bacteria: thymine (50), adenine (Io), guanine (I0), L-serine (200), and L-methionine (200) according to Samuel, D'Asi \& Rabinowitz (I970). Suspensions of $S$. faecalis $R$ were also prepared after growth on tryptose-glucose broth.

Bacillus megaterium was grown aerobically at $37^{\circ} \mathrm{C}$ in medium $\mathrm{AI}_{1}$ (White, 1972) with either D-biotin (I $\mu \mathrm{g} / \mathrm{l}$ ) or L-aspartate (roo $\mathrm{mg} / \mathrm{l}$ ) as supplement.

The bacteria were harvested, washed twice in saline $(\mathrm{NaCl} ; 0.9 \%, \mathrm{w} / \mathrm{v})$, resuspended in phosphate buffer (5o mM; $\mathrm{NaH}_{2} \mathrm{PO}_{4}: \mathrm{K}_{2} \mathrm{HPO}_{4}, \mathrm{pH} 6.5$ ) and autoclaved at $\mathrm{I} 20^{\circ} \mathrm{C}$ for $\mathrm{I} 5 \mathrm{~min}$ as $10 \mathrm{ml}$ samples (containing approximately $\mathrm{I}^{\mathbf{1 0}}$ bacteria/ml) in $100 \mathrm{ml}$ Erlenmeyer flasks.

Growth of Dictyostelium discoideum. Myxamoebae of strain AX-2 (ATCC24397), a derivative of the wild-type strain $\mathrm{NC}_{4}$, were maintained in $\mathrm{HL}_{5}$ medium containing glucose $(86 \mathrm{mM})$ according to Watts \& Ashworth (1970). Inocula were prepared by washing three times with phosphate buffer $(50 \mathrm{mM}, \mathrm{pH} 6.5)$ and resuspending at a final concentration of $10^{6}$ myxamoebae $/ \mathrm{ml}$. Samples $(0.1 \mathrm{ml})$ of this suspension were added to the suspensions of autoclaved bacteria ( $(\mathrm{O} \mathrm{ml})$ to give an initial concentration of $10^{4}$ myxamoebae $/ \mathrm{ml}$. The cultures were then incubated at $23{ }^{\circ} \mathrm{C}$ with shaking and the number of myxamoebae was determined at intervals by counting using a haemocytometer.

Chemicals. Thiamin $\mathrm{HCl}$, thiamin pyrophosphate $\mathrm{HCl}$, DL- $\alpha$-lipoic acid, pyridoxal $\mathrm{HCl}$, D-biotin, and avidin (I mg binds $14 \mu \mathrm{g}$ D-biotin) were purchased from Sigma. The sources of the other vitamins were: Koch-Light Laboratories Ltd (nicotinic acid, folic acid, calcium D-pantothenate) and BDH (cyanocobalamin). A sample of calcium 5-formyl tetrahydropteroylglutamate (leucovorin) was kindly provided by Dr P. J. White.

\section{RESULTS}

\section{Requirement for lipoate}

A possible requirement for lipoate was first indicated by the observation that $D$. discoideum would not grow in association with viable cultures of $E$. coli w I 485 lip 2 , defective in lipoate biosynthesis, on plates of glucose minimal medium supplemented with acetate plus succinate, although it grew normally when the medium contained lipoate. Further tests designed to determine whether this was due to a nutritional requirement for lipoate or to inhibition of myxamoebal growth by the accumulation of toxic metabolic products by the lipoate auxotroph, were performed with the lipoamide dehydrogenase mutant E. coli T3A58lpdr. This strain has an obligatory requirement for acetate plus succinate for growth on glucose and, by lacking functional pyruvate and $\alpha$-ketoglutarate dehydrogenase complexes, it exhibits a deranged glucose metabolism similar to that of the lipoate mutant under the same conditions. However, the myxamoebae grew well in association with the lipoamide dehydrogenase mutant and it was concluded that the failure to grow with the lipoate mutant was due to a nutritional dependence on lipoate.

Experiments with liquid cultures in which the myxamoebae were provided with heat-killed suspensions of bacteria deficient in lipoate confirmed that $D$. discoidewm has a nutritional 


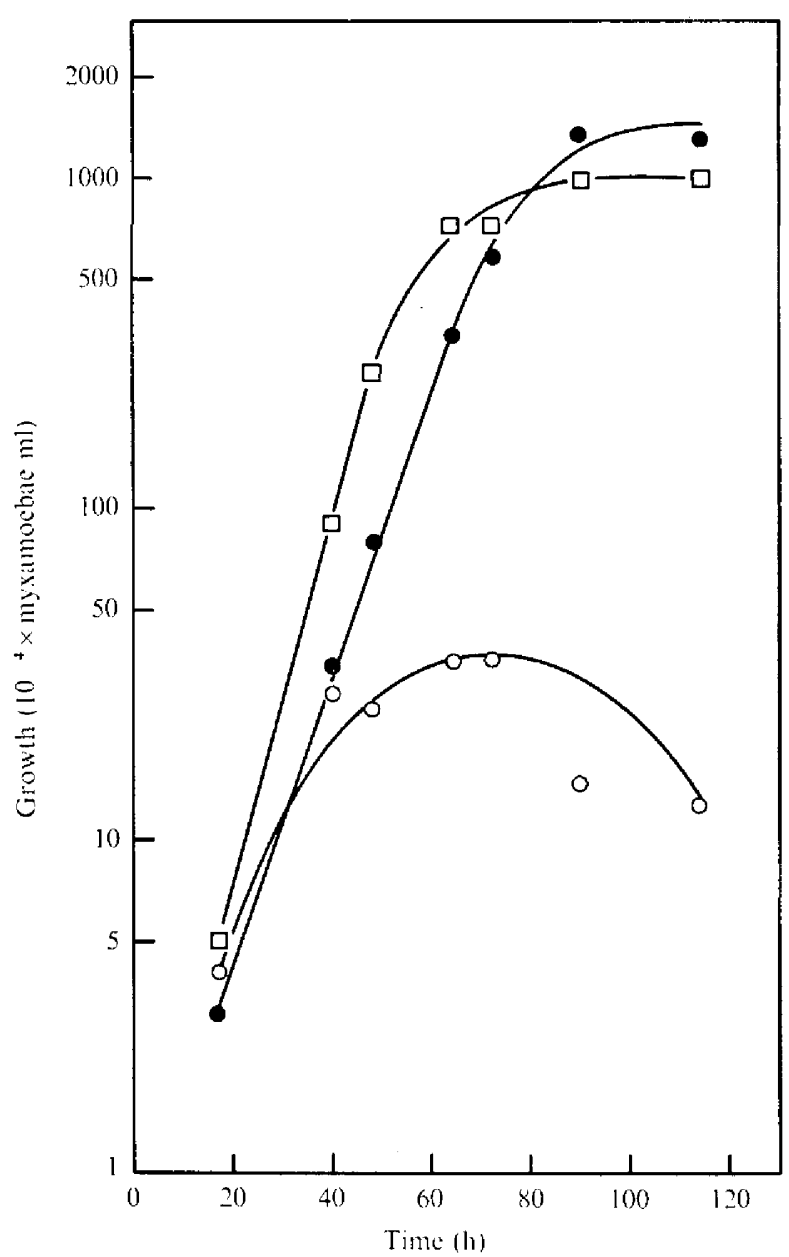

Fig. I. Growth of D. discoideum with E. coli wi 485 lipz as substrates. O, Growth with wI 485 lip2 depleted of lipoate; $O$, growth with wi 485 lip 2 containing lipoate; $\square$, growth with lipoate-deficient W1485lip2 plus exogenous lipoate (final concn $0.2 \mu \mathrm{g} / \mathrm{ml}$ ).

requirement for lipoate (Fig. I). With lipoate-grown WI485lip2 the growth was the same as with the parental prototrophic strain wi485. However, the growth yield was greatly reduced with lipoate-deficient suspensions as substrate but the yield could be restored by addition of exogenous lipoic acid. The results also indicate that the myxamoebae can use free lipoic acid, since in these experiments the bacterial suspensions are denatured and therefore incapable of elaborating the growth factor. Neither acetate ( 2 or $4 \mathrm{~mm}$ ) nor a mixture of acetate plus succinate (each at 2 or $4 \mathrm{~mm}$ ) replaced lipoate. Hence the myxamoebae have an obligatory requirement for lipoate, unlike the lactic acid bacteria or mutants of $E$. coli where it can be replaced by acetate or acetate plus succinate.

Since the experiments with liquid cultures gave quantitative results rather than the qualitative results obtained by dual culturing on solid medium, the former procedure was adopted in all subsequent experiments. 


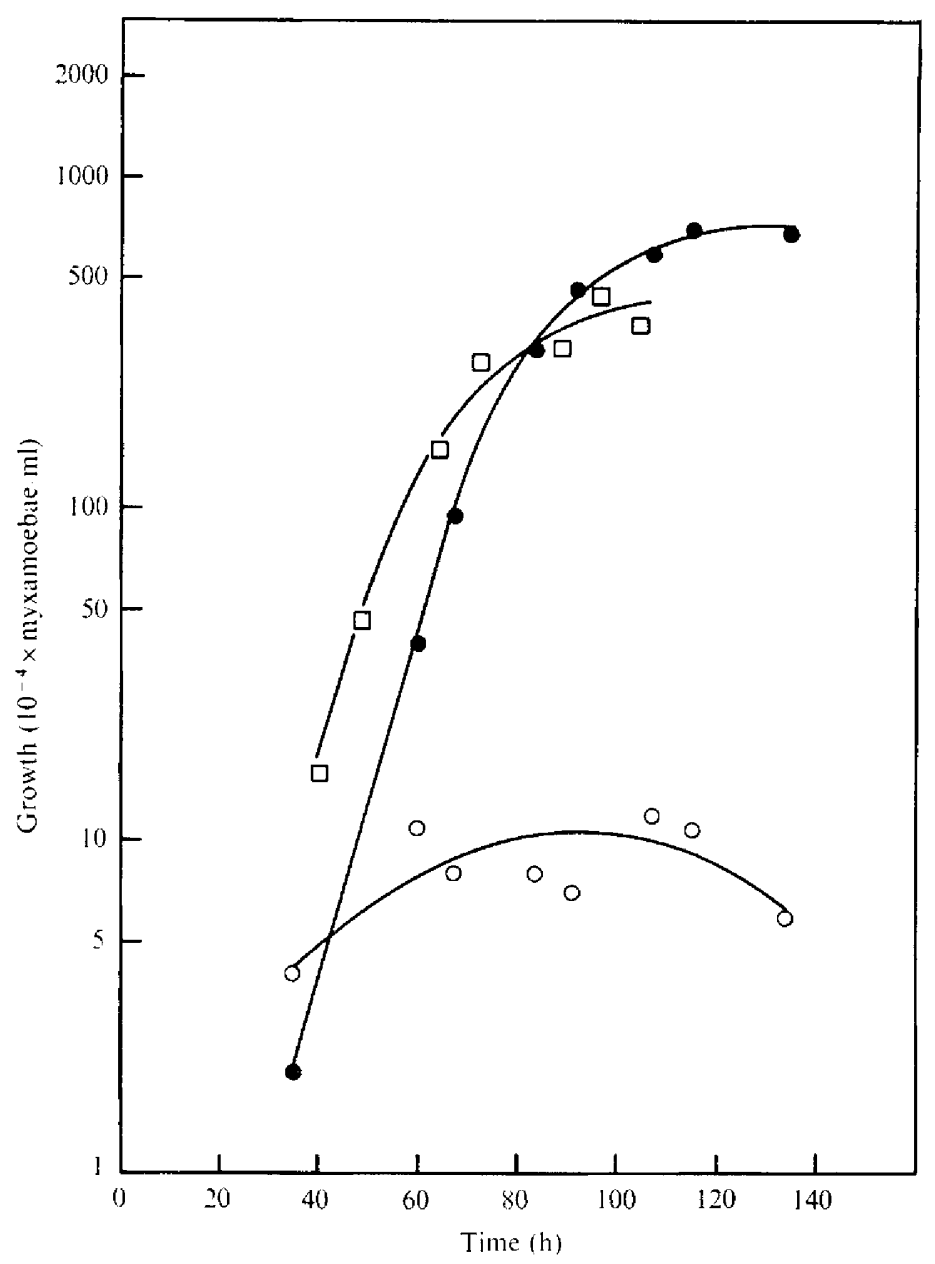

Fig. 2. Growth of $D$. discoideum with $E$, coli $273-384$ as substrate. $O$, Growth with 273-384 depleted of folate; 0 , growth with 273-384 containing folate (as a result of being grown with $p$-aminobenzoate); $\square$, growth with $273-384$ depleted of folate plus exogenous folic acid ( $2 \mu \mathrm{g} / \mathrm{ml})$.

\section{Requirement for folate}

Streptococcus faecalis $R$ would have been the preferred organism with which to obtain cell suspensions depleted for folate or vitamin $B_{6}$ because these growth factors can be replaced very effectively; folate by thymine plus adenine, guanine, serine and methionine (Stokes, 1944; Samuel et al. 1970) and vitamin $\mathrm{B}_{6}$ by D-alanine (Holden, Furman \& Snell, 1949). Unfortunately, although $D$. discoideum grew well on autoclaved suspensions of $S$. faecalis grown on tryptose-glucose broth, it grew extremely slowly with a very low yield on $S$. faecalis that had been grown in the defined media. This was true for vitamin-sufficient and vitamin-deficient bacteria, and myxamoebal growth was not improved by supplying the vitamins exogenously. However, the $p$-aminobenzoate auxotroph of $E$. coli, 273-384, grown in the presence of $p$-aminobenzoate or its replacement mixture, proved very satisfactory for obtaining substrates containing folate or depleted of folate. The myxamoebae grew very poorly on folate-deficient bacteria (Fig. 2) but the yield was increased some 40 -fold 


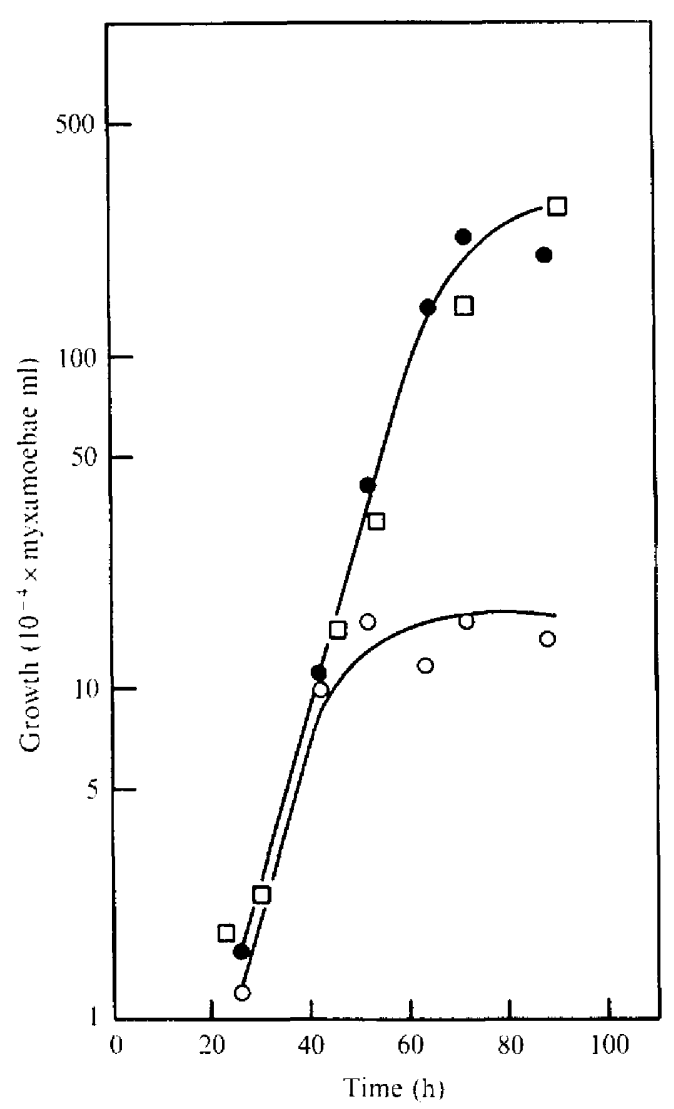

Fig. 3. Growth of $D$. discoideum with $E$. coli $\mathrm{Hfr}$ as substrate. Myxamoebae were grown with E. coli $\mathrm{HfrH}$ depleted of thiamin to $5.2 \times 10^{6}$ myxamoebae $/ \mathrm{ml}$. These organisms were then used to inoculate further cultures. $\mathrm{O}$, Growth with $\mathrm{Hfr}$ depleted of thiamin;, growth with $\mathrm{HfrH}$ depleted of thiamin plus exogenous thiamin $(50 \mu \mathrm{g} / \mathrm{ml}) ; \square$, growth with $\mathrm{HfrH}$ that had been grown in medium containing thiamin $(5 \mu \mathrm{g} / \mathrm{ml})$.

by adding folic acid (pteroylglutamic acid). The reduced derivative leucovorin produced the same response but pteroic acid and $p$-aminobenzoate were without effect. Higher conjugates of folic acid were not tested. These results clearly indicate that $D$. discoideum requires folate for growth.

\section{Requirement for thiamin}

A requirement for thiamin was demonstrated by growing the myxamoebae on thiaminstarved E. coli strain Hfru (Fig. 3). The effect was best seen when the myxamoebal inoculum was itself depleted of the growth factor by prior growth on thiamin-depleted $E$. coli. Addition of thiamin pyrophosphate $(50 \mu \mathrm{g} / \mathrm{ml})$ restored myxamoebal growth to exactly the same extent as thiamin.

\section{Requirement for biotin}

Bacillus megaterium 7581 can be made partially deficient in biotin by growth at $37^{\circ} \mathrm{C}$ with L-aspartate (Al-ssum \& White, 1974). Myxamoebal growth with the biotin-deficient bacteria as substrate was similar to growth with the bacteria grown with biotin. However, addition of avidin to sequester any biotin in the cultures caused a marked reduction in 


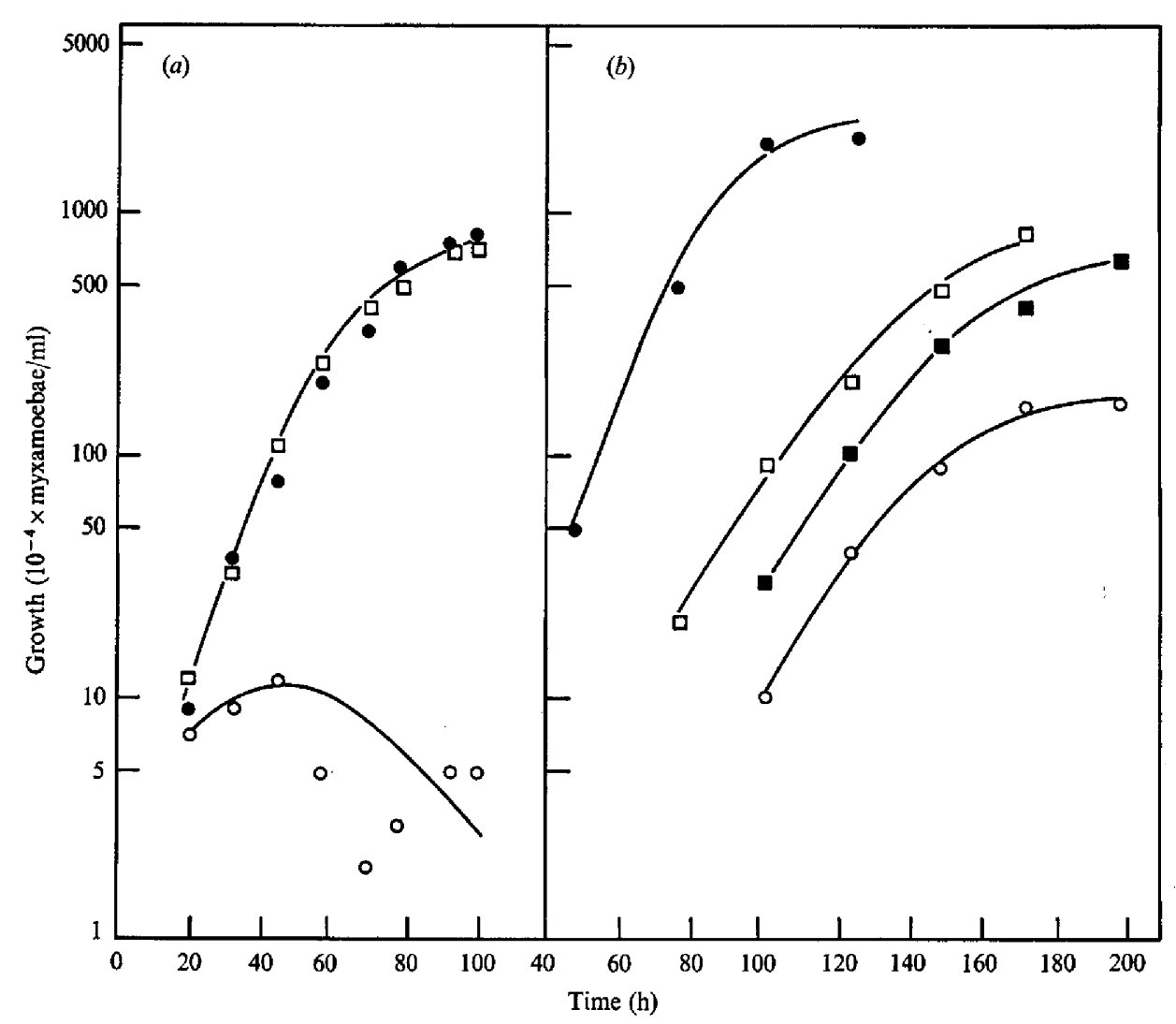

Fig. 4. (a) Growth of D. discoideum with B. megaterium $75^{81} \mathrm{I}$ as substrate. Myxamoebae were grown to $4 \cdot \mathrm{I} \times 10^{6}$ myxamoebae/ml with $B$. megaterium $758 \mathrm{I}$ depleted of D-biotin by growth with $\mathrm{L}-$ aspartate and were then used to inoculate further cultures. $O$, Growth with biotin-depleted 758I plus avidin $(0.2 \mathrm{mg} / \mathrm{ml})$; $O$, growth with biotin-depleted 7581 plus exogenous D-biotin (Io $\mu \mathrm{g} / \mathrm{ml}$ ) plus exogenous avidin $(0.2 \mathrm{mg} / \mathrm{ml}) ; \square$, growth with 7581 containing biotin. $(b)$ Growth of $D$. discoideum with $E$. coli $\mathrm{kB70}$ as substrate. Myxamoebae were grown to $3.7 \times 10^{6}$ myxamoebae $/ \mathrm{ml}$ with $E$. coli $\mathrm{kB} 70$ depleted of biotin and were then used to inoculate further cultures. $O$, Growth with KB70 depleted of biotin; - growth with KB70 containing biotin; $\square$, growth with biotindepleted KB70 plus exogenous D-biotin (IO $\mu \mathrm{g} / \mathrm{ml}) ; \boldsymbol{\square}$, growth with biotin-depleted KB70 plus exogenous avidin $(0 . \mathrm{I} \mathrm{mg} / \mathrm{ml})$ and exogenous D-biotin $(35 \mu \mathrm{g} / \mathrm{ml})$. No growth could be detected when myxamoebae were added to biotin-depleted KB70 plus exogenous avidin $(0.1 \mathrm{I} \mathrm{mg} / \mathrm{ml})$.

myxamoebal growth but growth was restored by addition of an excess of exogenous biotin (Fig. $4 a$ ). This indicates that the myxamoebae require biotin.

The biotin requirement was also demonstrated by using a biotin auxotroph of $E$. coli KB70 as substrate. As for thiamin, the requirement was more apparent when the myxamoebal inoculum was depleted of biotin by prior growth on the biotin-starved auxotroph. Slow growth occurred after a relatively long lag period on the biotin-deficient substrate (Fig. $4 b$ ). Addition of exogenous biotin shortened the lag period and improved the growth yield but the growth rate (and extent of growth) remained poorer than in control cultures where the substrate bacteria had been grown with biotin. Avidin had effects similar to those with cultures of $B$. megaterium. Since growth with biotin-deficient KB70 plus exogenous biotin was much poorer than growth with biotin-grown $\mathrm{KB} 7 \mathrm{O}$, it is possible that there is in addition 
to biotin a partial requirement for a product or products of biotin-dependent metabolism. Such compounds must presumably be provided by the partially depleted cultures of $B$. megaterium.

\section{Requirements for other vitamins}

Similar tests were performed with auxotrophs of $E$. coli depleted on pantothenate, nicotinate or vitamin $B_{6}$ but no significant lowering of the myxamoebal growth rate or yield could be detected. This could indicate that the auxotrophs were insufficiently depleted for demonstrating requirements for these vitamins or that the myxamoebae could synthesize them. In particular, nicotinate could be synthesized from tryptophan by means of the pathway found in fungi (Morris, 1962).

It may be concluded that $D$. discoideum does not require cobalamin since it grows well with $E$. coli which does not synthesize this vitamin (Friedmann \& Cagen, 1970). Moreover, growth of the myxamoebae was not affected by addition of cyanocobalamin to the cultures or by use, as the substrate, of $E$. coli grown with cyanocobalamin. Similarly, it would appear that there is no requirement for ubiquinone, since there was little impairment of myxamoebal growth when $E$. coli $\mathrm{AN} 385$ deficient in ubiquinone was the substrate and myxamoebae grew well with $B$. megaterium (Fig. $4 a$ ) which does not synthesize ubiquinone (Bishop, Pandya \& King, 1962). Myxamoebae also grew extremely well with Aerobacter aerogenes NCTC4I 8 (Watts, unpublished observation) which does not synthesize vitamin $\mathrm{K}$ when grown aerobically (Bishop et al. 1962), likewise indicating the absence of a requirement for vitamin $K$.

\section{DISCUSSION}

To obtain a chemically defined minimal medium supporting the growth of a microorganism, it has been usual to find a relatively complex but defined medium which supports growth, and then to identify essential and non-essential components by studying the effects of their omission. No defined medium has been found for $D$. discoideum, but the use of natural substrates (bacteria) deficient in specific metabolites offered a means of identifying some of its essential growth factors. Using auxotrophs of E. coli depleted of vitamins by growth in vitamin replacement media or by starvation in vitamin-deficient media, the results indicate that lipoate, folate, thiamin and biotin are essential growth factors for $D$. discoideum. Requirements for folate, thiamin and biotin are not unusual in micro-organisms but only a few species, e.g. Tetrahymena pyriformis (geleii) and Corynebacterium bovis 187 , have an absolute requirement for lipoate (Stokstad, Seaman, Davis \& Hutner, 1956; Reed, 1957). It is also noteworthy that folic acid is chemotactic to $D$. discoideum and may be responsible for attracting myxamoebae to bacterial substrates (Pan, Hall \& Bonner, 1972).

This method of identifying essential growth factors requires that two conditions should be satisfied. First, myxamoebal growth must be significantly impaired with the deficient substrate, and second, growth must be restored by some form of the vitamin or growth factor when supplied exogenously. Both criteria are important, because it is well known that changes in environment can cause striking changes in bacterial composition (Herbert, 196I) and differences in myxamoebal growth rates or yields could be secondary consequences of the methods used to deplete the bacteria unless restoration of growth is demonstrated by some form of corresponding growth factor. The extent of restoration by exogenous factors may likewise be affected by secondary effects on the composition of the depleted bacteria but other considerations, such as the uptake of exogenous vitamins and the provision of acceptable forms of vitamin which $D$. discoideum can use, may be more important. Nevertheless, both of the above criteria were satisfied by the four vitamins identified as growth 
factors for $D$. discoideum and in no case did a growth-limited culture of myxamoebae fail to respond to the corresponding vitamin. The optimal concentration for each vitamin was not determined.

The method is clearly limited to the use of bacteria which can be used as substrates by $D$. discoideum and by the availability of species or auxotrophs which can be depleted of specific growth factors. It also suffers from the problem of drawing meaningful conclusions when the myxamoebal growth pattern is unaffected or only slightly altered by growth on depleted bacteria. Thus, with the mutants depleted of pantothenate, nicotinate or vitamin $\mathbf{B}_{6}$, the results could indicate that the myxamoebae have no requirement for these vitamins or that the bacteria were not sufficiently depleted to demonstrate a myxamoebal requirement. In this respect, it is unfortunate that $S$. faecalis, which can be severely depleted of vitamin $\mathbf{B}_{6}$, was such a poor substrate after growth in defined medium. This could be a direct expression of the effect of the environment on bacterial composition, or it may be due to the uptake by $S$. faecalis of growth factors which are essential for $D$. discoideum but non-essential for S. faecalis, during its growth on complex medium.

We thank those who generously provided some of the bacterial cultures used in this work, and S. Hall and I. T. Creaghan for skilled technical assistance.

\section{REFERENCES}

AdhyA, S. L. \& Shapiro, J. A. (I969). The galactose operon of E. coli K-I2. I. Structural and pleiotropic mutations of the operon. Genetics 62, 23 I-247.

AL-sSum, R. M. \& WHITE, P. J. (I974). Biotin deficiency in Bacillus megaterium. Proceedings of the Society for General Microbiology $\mathbf{r}, 69-70$.

Bachmann, B. J. (1972). Pedigrees of some mutant strains of Escherichia coli K-12. Bacteriological Reviews $3^{6,525-557 .}$

Bishop, D. H. L., PANDYA, K. P. \& King, H. K. (1962). Ubiquinone and vitamin K in bacteria. Biochemical Journal 83, 606-6I4.

Bukhari, A. I. \& TAYlor, A. L. (I97I). Genetic analysis of diaminopimelic acid- and lysine-requiring mutants of Escherichia coli. Journal of Bacteriology 105, 844-854.

FriedmanN, H. C. \& CAGEN, L. M. (I970). Microbial biosynthesis of $\mathrm{B}_{12}$-like compounds. Annual Review of Microbiology 24, $159-208$.

Gibson, F. \& Woods, D. D. (1960). Synthesis of methionine by suspensions of Escherichia coli. Biochemical Journal 74, 160-172.

Gutst, J. R. \& CReAGHAN, I. T. (I973). Gene-protein relationships of the $\alpha$-keto acid dehydrogenase complexes of Escherichia coli $\mathrm{k} 12$ : isolation and characterization of lipoamide dehydrogenase mutants. Journal of General Microbiology 75, 197-2 Io.

Herbert, D. (I96I). The chemical composition of micro-organisms as a function of their environment. Symposia of the Society for General Microbiology Ir, 39I-4I 6.

Herbert, A. A. \& Guest, J. R. (I968). Biochemical and genetic studies with lysine + methionine mutants of Escherichia coli: lipoic acid and $\alpha$-ketoglutarate dehydrogenase-less mutants. Journal of General Microbiology 53, 363-38x.

Holden, J. T., Furman, C. \& SNell, E. E. (I949). D-Alanine and vitamin B $_{6}$ content of micro-organisms. Journal of Biological Chemistry $\mathbf{1 7 8}, 789-797$.

Lascelles, J. \& Woods, D. D. (I954). The synthesis of serine and Leuconostoc citrovorium factor by cell suspensions of Streptococcus faecalis R. Biochemical Journal $\mathbf{5 8}, 486-497$.

Morris, J. G. (1962). The synthesis of vitamins and coenzymes. In The Bacteria, vol. 3, pp. 253-294. Edited by I. C. Gunsalus and R. Y. Stanier. New York and London: Academic Press.

Morris, J. G. \& Woods, D. D. (1959). Inter-relationships of serine, glycine and vitamin $B_{6}$ in the growth of mutants of Escherichia coli. Journal of General Microbiology 20, 576-596.

PAN, P., Hall, E. M. \& Bonner, J. T. (I972). Folic acid as a second chemotactic substance in the cellular slime moulds. Nature New Biology 237, I81-182. 
REED, L. J. (1957). The chemistry and function of lipoic acid. In Advances in Enzymology, vol. 18, pp. 319347. Edited by F. F. Nord. New York: Interscience Publishers.

Rolfe, B. \& ONODERA, K. (1972). Genes, enzymes and membrane proteins of the nitrate respiration system of Escherichia coli. Journal of Membrane Biology 9, 195-207.

Samuel, C. E., D'Asi, L. \& Rabinowitz, J. C. (I970). Evidence against the folate-mediated formylation of formyl-accepting methionyl transfer ribonucleic acid in Streptococcus faecalis R. Journal of Biological Chemistry 245, 5I I 5-5I 2 I.

Stokes, J. L. (1944). Substitution of thymine for folic acid in the nutrition of lactic acid bacteria. Journal of Bacteriology 48, 20I-209.

Stokstad, E. L. R., Seaman, G. R., Davis, R. J. \& Hutner, S. M. (I956). Assay of thioctic acid. In Methods of Biochemical Analysis, vol. 3, pp. 23-47. Edited by D. Glick. New York: Interscience Publishers.

Vogel, H. \& BonNer, D. M. (1956). A convenient growth medium for Escherichia coli and some microorganisms. Microbial Genetics Bulletin 13, 43-44.

WATts, D. J. \& Ashworth, J. M. (1970). Growth of myxamoebae of the cellular slime mould Dictyostelium discoideum in axenic culture. Biochemical Journal 119 , 17 I-I 74.

WhIre, P. J. (1972). The nutrition of Bacillus megaterium and Bacillus cereus. Journal of General Microbiology $7 \mathbf{r}, 505-514$.

Young, I. G., LePpIK, R. A., Hamilton, J. A. \& Gibson, F. (1972). Biochemical and genetic studies on ubiquinone biosynthesis in Escherichia coli K-12: 4-hydroxybenzoate octaprenyltransferase. Journal of Bacteriology 110, 18-25. 